\title{
Regulatory Pathway
}

National Cancer Institute

\section{Source}

National Cancer Institute. Regulatory Pathway. NCI Thesaurus. Code C19779.

An elaboration of the known or inferred interactions controlling the expression of a product. 